\title{
Finance and Synchronization ${ }^{\text {is }}$
}

\author{
Ambrogio Cesa-Bianchi ${ }^{\dagger} \quad$ Jean Imbs $^{\ddagger} \quad$ Jumana Saleheen $^{\S}$
}

August 3, 2016

\begin{abstract}
In the workhorse model of international real business cycles, financial integration exacerbates the cycle asymmetry created by country-specific supply shocks. The prediction is identical in response to purely common shocks in the same model augmented with simple country heterogeneity (e.g., where depreciation rates or factor shares are different across countries). This happens because common shocks have heterogeneous consequences on the marginal products of capital across countries, which triggers international investment. In the data, filtering out common shocks requires therefore allowing for country-specific loadings. We show that finance and synchronization correlate negatively in response to such common shocks, consistent with previous findings. But finance and synchronization correlate non-negatively, almost always positively, in response to purely country-specific shocks.
\end{abstract}

Keywords: Financial linkages, Business cycles synchronization, Contagion, Common Shocks, Idiosyncratic Shocks.

JEL Codes: E32, F15, F36, G21, G28.

\footnotetext{
${ }^{2}$ We would like to thank Michael Binder, Giancarlo Corsetti, Richard Harrison, Sujit Kapadia, Robert Kollmann, Eric Monnet, Jose-Luis Peydro, Franck Portier, Daniele Siena, Konstantinos Theodoridis, and Gregory Thwaites for helpful comments and suggestions. We are also grateful for comments from attendants to the 10th Annual Workshop on "The Macroeconomics of Global Interdependence" in Dublin, the IAAE 2016 Annual Meetings, the "Workshop on International Business Cycles" at Banque de France, and seminar participans at the ECB and the Bank of England. Financial support from the Chaire Banque de France at the Paris School of Economics is gratefully acknowledged. The views expressed in this paper are solely those of the authors and should not be taken to represent those of the Bank of England.

${ }^{\dagger}$ Bank of England and CfM. Email: ambrogio.cesa-bianchi@bankofengland.co.uk.

${ }^{\ddagger}$ Paris School of Economics (CNRS), and CEPR. Email: jeanimbs@gmail.com.

${ }^{\S}$ Bank of England. Email: jumana.saleheen@bankofengland.co.uk.
} 


\section{Introduction}

Understanding how disturbances propagate across countries is of first-order importance. Openness in general is often singled out as a plausible and significant propagation channel. Historically openness to goods trade came first, and there is robust evidence that trade partners display correlated business cycles. ${ }^{1}$ The global consequences of the 2007-2008 recession have contributed to shifting the focus on the importance of financial linkages. While it was always important to assess how financial integration affects the international synchronization of business cycles, the question has become of paramount importance since 2008, for policy-makers and researchers alike.

In the canonical two-country real business cycles model with country-specific productivity shocks (Backus, Kehoe, and Kydland, 1992, BKK henceforth) capital flows to wherever returns are higher. Therefore, greater financial linkages lower the international synchronization of business cycles in response to country-specific shocks. But in a similar two-country model, augmented with credit or collateral constraints, a country-specific shock that makes the constraint binding at home is contagious abroad as domestic agents recall foreign assets to meet the constraint. ${ }^{2}$ There is no reason for the constraint to become binding in response to a specific kind of shock: Demand, supply, or even financial shocks may all create a binding constraint, and so trigger contagion. Here, therefore, greater financial linkages can increase synchronization in response to country-specific shocks. The common feature of these models is that they analyze the consequences of purely idiosyncratic, country-specific shocks, with ambiguous predictions.

It is not difficult to see that similar predictions arise from the canonical international RBC model in response to common shocks, provided that some mild heterogeneity exists across countries. For instance, countries with different depreciation rates or different capital shares react to the same technology shock with different magnitudes, driving a gap between the marginal products of capital on impact. As a result, international investment rises, and the international synchronization of cycles falls. In fact, the predictions of BKK with homogeneous countries and idiosyncratic

\footnotetext{
${ }^{1}$ Among many others, see Frankel and Rose (1998) or Baxter and Kouparitsas (2005).

${ }^{2}$ See Devereux and Yetman (2010), Dedola and Lombardo (2012), Kalemli-Ozcan, Papaioannou, and Perri (2013), or Allen and Gale (2000) offer different versions of the mechanism, where constraints are at bank or firm level.
} 
shocks are observationally equivalent to its predictions with heterogeneous countries and common shocks, for plausible parametrization of heterogeneity.

Figure 1 Impulse Response Functions in Variants of BKK
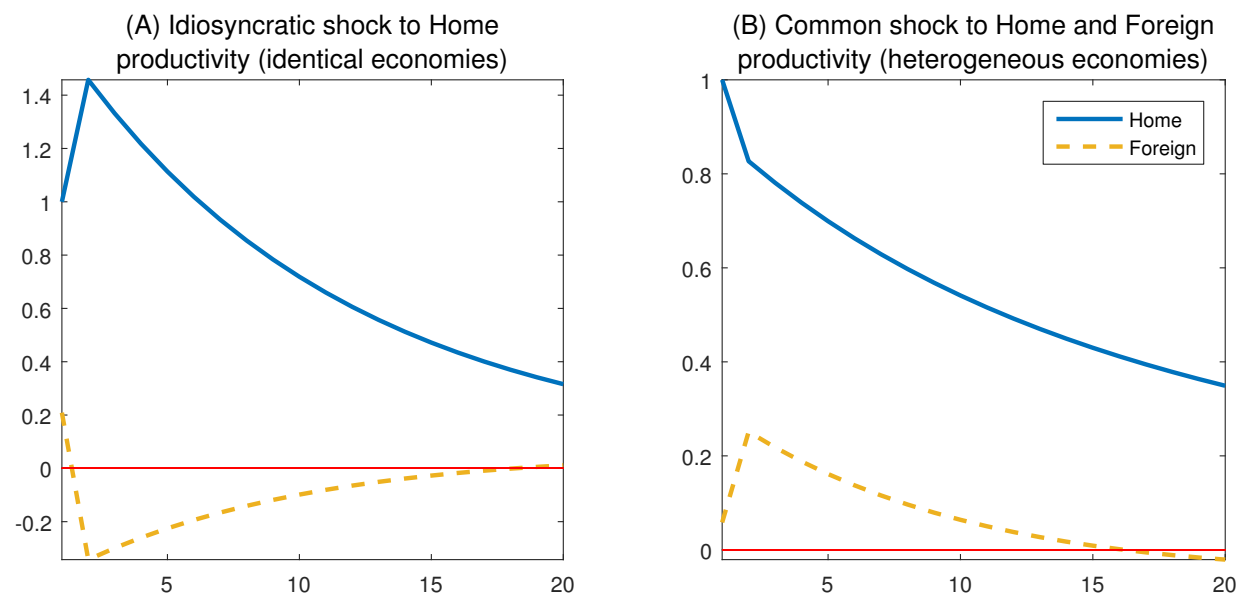

Note. Panel (A) reports the impulse response functions to a producivity shock in the Home country, in the case where the Home and Foreign economies are identical. The chart reports the response of Output in the Home (solid line) and Foreign (dashed line) economies. Panel (B) reports the same impulse response functions for a common shock (i.e., a shock that raises productivity by the same amount in the Home and Foreign economy) when the two economies are heterogeneous. The source of heterogeneity is the share of capital in the production function $(\theta)$. While in Panel (A), as in BKK, we set $\theta_{H}=\theta_{F}=0.36$, in Panel (B) we set $\theta_{H}=0.44$ and $\theta_{F}=0.32$. All remaining parameters are identical to BKK (except for the time to build, set to 1). The size of the shock has been normalized so that it increases Home output by 1 percent.

Figure 1 plots the responses of output to a technology shock as implied by two versions of BKK. Panel (A) reproduces the well known results in BKK in response to a shock to productivity in the Home country, under the conventional symmetric calibration. Panel (B) introduces a version of BKK that deviates from the original in two dimensions: (i) the productivity shock is common, i.e. is perfectly synchronized across countries; and (ii) the share of capital is heterogeneous across countries, taking values of 0.44 in the Home country, and 0.32 in the Foreign country (a dispersion consistent with the values for Portugal and Japan reported in the Penn World Tables, version 8.1, see Appendix A1). On impact, the responses of Output in Figure 1 are virtually indistinguishable across Panels.

To investigate the ambiguous link between finance and synchronization in re- 
sponse to country-specific shocks, it is therefore important to control for common shocks that are allowed to have different effects across countries. The conventional approach consists in including time effects or trends in an estimation where the dependent variable is a measure of synchronization. This does eliminate the effects of those shocks that by construction have identical effects on both economies. But it does not eliminate common shocks with heterogeneous effects, that are likely to exist in a world where countries display fundamental differences, if only in the parametrization of their production function.

To eliminate common shocks with heterogeneous effects, alternative approaches are necessary. This paper follows the simplest possible approach: We perform a principal component analysis on the panel of GDP growth rates, which allows us to separate common shocks with heterogeneous effects (i.e., the country-specific loadings on the principal components) and idiosyncratic shocks. In the main text, the loadings are assumed constant, but for robustness we also repeat the analysis estimating a factor model that allows for time-varying loadings using Bayesian techniques. Both decompositions have the advantage of simplicity and an established place in the literature. There are of course many alternatives, which we leave for further work. However, we also provide analytically a general intuition for the results of the paper, that is not conditioned on one specific way to isolate common shocks with heterogeneous effects.

Conditional on common shocks, we find that finance and synchronization correlate negatively. The result supports Kalemli-Ozcan, Papaioannou, and Peydro (2013) (KPP henceforth), who show that an increase in financial integration causes a fall in business cycle synchronization in 18 OECD countries. But our interpretation differs from theirs. According to KPP, the data support the view that financial flows are efficient in their quest for high returns, behaving exactly as the canonical international RBC model predicts in response to idiosyncratic shocks. We conclude instead that the finding arises in response to common shocks with heterogeneous effects. Now these effects are given parametrically: They represent the response of country $i$ to a common shock, which differs from the response of country $j$ because, say, the countries have different capital shares. The difference in responses is therefore a constant, given by the differences in deep parameters of the model. Empirically, the response of a given country to the common shock is given by the loading in the principal component estimation: We call it the country's "elasticity 
of GDP". 3 Our results show that, in the cross-section, these elasticities are systematically related to capital flows. An interpretation of this finding is that capital flows are procyclical: That is, countries with elastic GDP are net recipients of international capital in years of global boom, but net contributors in years of global recession. ${ }^{4}$ We document this correlation in OECD data. In years of positive common shocks, net capital holdings increase in countries with elastic GDP, and fall in countries with inelastic GDP. The opposite tends to occur in years of negative common shocks.

In contrast, there is no systematic time pattern in the response of international investment to purely country-specific shocks: Source and destination countries change randomly over time, depending on the realization of the shocks. Interestingly, increases in financial linkages are almost always associated with more synchronized business cycles in response to country-specific shocks. The coefficient estimates are never negative, and significantly positive in 10 out of the 12 specifications we consider. ${ }^{5}$ This stands in contrast with common shocks, and suggests financial links may in fact foster the contagious propagation of country-specific shocks across borders. In theory, the result supports the existence of (endogenously binding) constraints: In response to country-specific shocks, financial flows may serve to alleviate collateral or balance sheet constraints, rather than to take advantage of attractive differentials between returns across countries.

Can we easily interpret common and idiosyncratic shocks in terms of changes in technology, in demand, or in financial health? This is an important question in light of the Great Recession of 2008, often understood as a financial shock that was fundamentally different from the preceding history. For instance, Kalemli-Ozcan, Papaioannou, and Perri (2013) construct a simple model that implies financial contagion via financial shocks, and show empirically that finance and synchronization moved in the same direction during the Great Recession. They interpret the shock in 2008 as fundamentally different from the preceding history during which finance

\footnotetext{
${ }^{3}$ Even when we allow for it, we find little time variation in the estimated factor loadings. See the robustness exercise in Section 4.

${ }^{4}$ (See, among others, Kaminsky, Reinhart, and Vegh, 2005, Rey, 2013, Broner, Didier, Erce, and Schmukler, 2013, Bruno and Shin, 2015).

${ }^{5}$ The two non-positive estimates arise when synchronization is measured by Pearson correlation coefficients, which are known to be problematic when the variance of the underlying shocks is varying over time. See Forbes and Rigobon (2002).
} 
and synchronization went in opposite directions. We emphasize that our decomposition is just a generalization of the conventional empirical approach that controls for common shocks using year effects: Our common shocks are more general, and of course they nest the special case of common shocks with similar effects across countries. What we identify as "idiosyncratic shocks" is merely a subset of the shocks considered, among others, in Kalemli-Ozcan, Papaioannou, and Perri (2013), one that controls for common shocks with heterogeneous effects. There is neither more nor less reason to call these shocks "demand", "supply" or "financial" in this paper than there are elsewhere in this literature. We argue it is only idiosyncratic shocks that have ambiguous consequences on the link between finance and synchronization, not common ones. The claim is true irrespective whether these shocks are to the supply, the demand, or the financial side of the economy.

Recent Literature. Unsurprisingly, the recent years have witnessed a plethora of models where financial integration results in contagion. Early contributions include Devereux and Yetman (2010) where contagion is triggered by leverage-constrained investors, whose constraint becomes binding in response to a country-specific shock (to supply, demand, or otherwise). As portfolios are modified accordingly, the leverage constraint becomes binding elsewhere, with contagious consequences. Devereux and $\mathrm{Yu}$ (2014) extend the model to investigate the welfare consequences of financial integration. Dedola and Lombardo (2012) emphasize the importance of globally correlated borrowing costs in creating contagious finance between leveraged investors. The common feature of these theories is the presence of financial frictions, which result in contagious country-specific shocks (to supply, demand, or otherwise) provided that they result in endogenously binding constraints.

The empirical literature is equally replete with analyses of whether financial linkages are contagious or not. In an early contribution, Morgan, Rime, and Strahan (2004) investigate how bank ownership across US states affect fluctuations in Gross State Products. They find the lifting of branching regulations between 1976 and 1994 resulted in synchronized states' business cycles. Imbs (2006) finds a similar result in a cross-section of countries, using alternative measures of international financial integration. Kalemli-Ozcan, Papaioannou, and Peydro (2013) argue the finding is driven by permanent features of country pairs, which result in both synchronized cycles and financial linkages. In 18 OECD countries, they show the link between finance and synchronization becomes negative once country-pair specific intercepts 
are accounted for. The results are confirmed by Duval, Li, Saraf, and Seneviratne (2016) in 63 advanced and emerging countries between 1995 and 2013. Monnet and Puy (2016) show that the share of the variance of GDP explained by global shocks is lowest during periods of financial integration, which suggests idiosyncratic shocks are more prevalent in those periods.

It is well known that the bulk of the volatility in GDP across countries can be explained by common shocks. In a series of influential papers, Kose, Otrok, and Whiteman (2003, 2008), Crucini, Kose, and Otrok (2011), or Hirata, Kose, and Otrok (2013) identify the contribution of common shocks (global or regional) to individual countries' business cycles. A key result is that shocks common to two or more countries constitute the main driver of business cycles in both the developed and developing worlds. The details of the decompositions depend on the sample of countries and time coverage; but common shocks rarely explain less than half of GDP growth volatility, and often more than 75 percent.

The possibility that common shocks have heterogeneous loadings is an old tradition in empirical macroeconomics. Forni and Reichlin (1998) identify sector-level effects of aggregate shocks in the US. Bernanke, Boivin, and Eliasz (2005) augment standard Vector Auto-Regressions with unobserved factors to identify their potentially heterogeneous consequences on economic activity. Mumtaz, Simonelli, and Surico (2011) extend the approach to an international context. Peersman and Smets (2005) identify heterogeneous effects of monetary shocks at sector level. Kilian (2008) shows the consequences of exogenous oil shocks are heterogeneous across G7 countries.

The rest of the paper is structured as followed. Section 2 presents the conventional estimation of the effects of finance on synchronization. Common shocks are discussed in terms of their theoretical impact on the correlation between finance and synchronization. Section 3 introduces the data that we use in the empirical analysis, and discusses the relevance of common vs. idiosyncratic shocks in GDP data. The decomposition is then used to discuss the effects of finance on synchronization. Section 4 discusses some extensions. Section 5 concludes. 


\section{Finance and Synchronization: Why Common Shocks Matter}

This Section first discusses the consequences of common shocks on business cycle synchronization, and then turns to the consequences of common shocks on the estimated effect of finance on synchronization.

\subsection{Synchronization}

It has become standard to measure the synchronization between two economies $i$ and $j$ on the basis of the absolute differential in GDP growth $\mathcal{S}_{i j, t}$ given by:

$$
\mathcal{S}_{i j, t}=-\left|y_{i, t}-y_{j, t}\right|
$$

where $y_{i, t}$ and $y_{j, t}$ are the growth rates of GDP in country $i$ and $j$ at time $t$. The definition is such that $\mathcal{S}_{i j, t}$ increases with the degree of synchronization, with negative values close to zero between synchronized countries.

The variable $S_{i j, t}$ presents two key advantages. First, it is readily observable at high frequencies, yearly or quarterly. Second, unlike the Pearson correlation coefficient, it is invariant to the volatility of the underlying shock (see Forbes and Rigobon (2002) and Corsetti, Pericoli, and Sbracia (2005)). However, its properties are ambivalent. Even if two countries respond in the same direction to a shock, i.e. co-movement is high, $S_{i j, t}$ can fall if the magnitude of the responses is different across countries. In other words, $S_{i j, t}$ conflates a measure of co-movement and a measure of dispersion. The same is of course not true of the more conventional Pearson correlation coefficient. ${ }^{6}$

The measure in equation (1) is now used widely, for example by Giannone, Lenza, and Reichlin (2010), Kalemli-Ozcan, Papaioannou, and Perri (2013), Kalemli-Ozcan, Papaioannou, and Peydro (2013), or IMF (2013) among others. Morgan, Rime, and Strahan (2004), Kalemli-Ozcan, Papaioannou, and Perri (2013), or Kalemli-Ozcan, Papaioannou, and Peydro (2013) introduce an alternative that controls for common shocks, given by:

$$
\mathcal{S}_{i j, t}^{e}=-\left|e_{i, t}-e_{j, t}\right|
$$

\footnotetext{
${ }^{6}$ Nor is it of the quasi-correlation coefficient in Duval, Li, Saraf, and Seneviratne (2016).
} 
where $e_{i, t}$ is a residual of a panel growth regression:

$$
y_{i, t}=\alpha_{i}+\gamma_{t}+e_{i, t}
$$

As is clear, $\mathcal{S}_{i j, t}^{e}$ controls for shocks that are common across the panel of GDP growth rates, but that are constrained to have homogeneous effects across countries.

This paper argues the existence of common shocks with country-specific effects alters the interpretation of $\mathcal{S}_{i j, t}$ (or $\mathcal{S}_{i j, t}^{e}$ ). To see this, assume the true model for GDP growth involves a vector of common shocks $\mathcal{F}_{t}^{y}$ with heterogeneous country loadings, i.e.:

$$
y_{i, t}=a_{i}^{y}+b_{i}^{y} \mathcal{F}_{t}^{y}+\varepsilon_{i, t}^{y} .
$$

where $a_{i}^{y}$ is the average growth of GDP in country $i, \varepsilon_{i, t}^{y}$ denotes the response of GDP growth to an idiosyncratic shock, and $b_{i}^{y}$ is the vector of country $i$ 's loading on a $f \times 1$ vector of common (to at least two countries) factors $\mathcal{F}_{t}^{y} \cdot{ }^{7}$ By definition, the synchronization measure in equation (1) can be re-written as:

$$
\mathcal{S}_{i j, t}=-\left|a_{i}^{y}-a_{j}^{y}+\left(b_{i}^{y}-b_{j}^{y}\right) \mathcal{F}_{t}^{y}+\varepsilon_{i, t}^{y}-\varepsilon_{j, t}^{y}\right| .
$$

The equilibrium response of synchronization to idiosyncratic shocks is given by:

$$
\mathcal{S}_{i j, t}^{\varepsilon}=-\left|\varepsilon_{i, t}^{y}-\varepsilon_{j, t}^{y}\right|
$$

which differs from $\mathcal{S}_{i j, t}$ because of the equilibrium response of GDP in both countries to the common shocks summarized in $\mathcal{F}_{t}^{y}$. Denote the guilty term by:

$$
\mathcal{S}_{i j, t}^{\mathcal{F}}=-\left|\left(b_{i}^{y}-b_{j}^{y}\right) \mathcal{F}_{t}^{y}\right|
$$

By definition, $\mathcal{S}_{i j, t}^{\mathcal{F}}$ varies with both dimensions of the panel, and so has the potential to affect the behaviour of $\mathcal{S}_{i j, t}$ meaningfully, even in a regression controlling for country-pair fixed and for year effects. Inasmuch as it only controls for common shocks with a single loading, $\mathcal{S}_{i j, t}^{e}$ suffers from the same potential issue.

Figure 2 reports the behaviour of the synchronization measure $\mathcal{S}_{i j, t}$ (solid line) in the cross-section of 18 advanced economies from 1980 to 2012, together with its

\footnotetext{
${ }^{7}$ This is a very standard assumption in the factor models literature. See Forni and Reichlin (1998) or Bernanke, Boivin, and Eliasz (2005).
} 
decomposition into $\mathcal{S}_{i j, t}^{\mathcal{F}}$ (dotted line) and $\mathcal{S}_{i j, t}^{\varepsilon}$ (dashed line). ${ }^{8}$ The recessions of 1991 and 2008 are associated with large falls in $S_{i j, t}$, a somewhat counter-intuitive feature of a synchronization measure. We conjecture this results from the heterogeneous responses of different countries to common shocks, and thus reflects the fact that $S_{i j, t}$ is a measure of dispersion rather than comovement. Even though most countries were moving in the same direction (for instance during the global recession of 2008-09), $\mathcal{S}_{i j, t}$ fell as the pace of the contraction in GDP was heterogeneous across countries. For instance, US annual GDP growth went from about -0.3 in 2008 to about -2.8 percent in 2009 , whereas UK GDP growth went from -0.3 to -4.3 percent. Even though both growth rates moved in the same direction, $\mathcal{S}_{i j, t}$ fell from 0 to -1.5 , and thus implied that the UK and the US became less synchronized.

Figure 2 The Evolution Of Synchronization (And Of Its IDIOSYNCRATIC ANd COMmon Components)

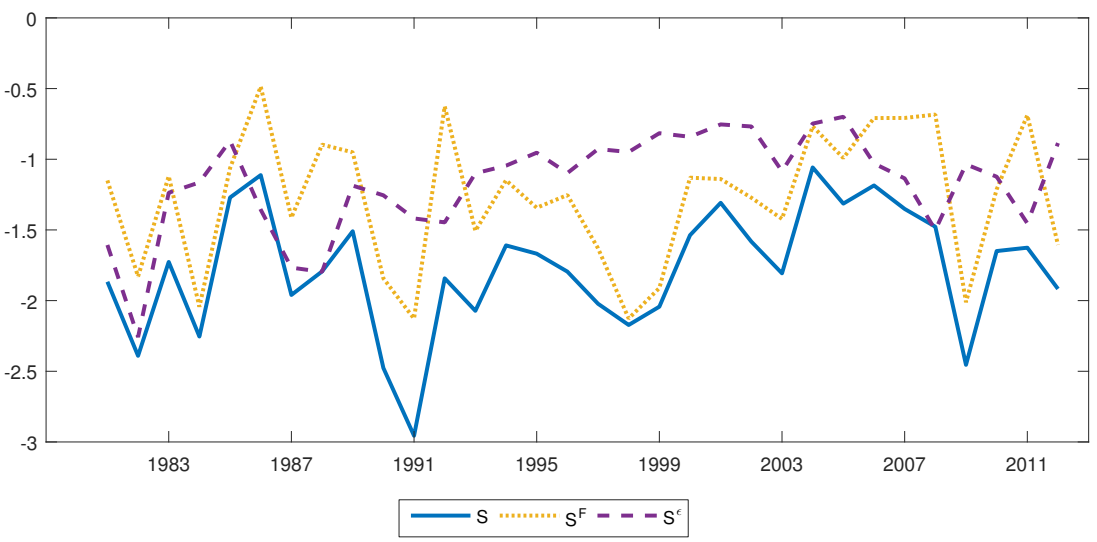

Note. The solid line plots the evolution over time of the average value of $\mathcal{S}_{i j, t}$ for the 1980-2012 period. The average is computed across 153 country pairs (our sample spans 18 countries) for each year. The chart also reports the crosssectional averages of the decomposition of $\mathcal{S}_{i j, t}$ into its idiosyncratic component $\left(\mathcal{S}_{i j, t}^{\epsilon}\right.$, dashed line) and its common component $\left(\mathcal{S}_{i j, t}^{\mathcal{F}}\right.$, dotted line). $\mathcal{F}_{t}$ has been proxied by the first 3 principal components on the panel of GDP growth rates (see details in Section 3 below). The averages are computed across 153 country pairs for each year over the 1980-2012 period.

The plots of $\mathcal{S}_{i j, t}^{\mathcal{F}}$ and $\mathcal{S}_{i j, t}^{\varepsilon}$ in Figure 2 confirm this conjecture, showing that the decline in $\mathcal{S}_{i j, t}$ observed during the 1991 or 2008 recessions is clearly associated

\footnotetext{
${ }^{8} \mathrm{~A}$ detailed description of the data and of the methodology to obtain a decomposition of $\mathcal{S}_{i j, t}$ into $\mathcal{S}_{i j, t}^{\mathcal{F}}$ and $\mathcal{S}_{i j, t}^{\varepsilon}$ is reported in Section 3.
} 
with common shocks and their heterogeneous impact, as $\mathcal{S}_{i j, t}^{\mathcal{F}}$ drops substantially in both cases. We emphasize this does not have to be the case: $\mathcal{S}_{i j, t}$ does not have to systematically take low values during recessions. The facts that it does in

OECD data, and that $\mathcal{S}_{i j, t}$ is highly positively correlated with $\mathcal{S}_{i j, t}^{\mathcal{F}}$ both suggest that common shocks with heterogeneous effects are relevant in the sample at hand. In contrast, $\mathcal{S}_{i j, t}^{\varepsilon}$ increases in 2008 , and does not fall in 1991. In fact, $\mathcal{S}_{i j, t}^{\varepsilon}$ reflects what is expected of an average of idiosyncratic shocks: Low volatility over the period, with average values much closer to zero than $\mathcal{S}_{i j, t}$ or $\mathcal{S}_{i j, t}^{\mathcal{F}}$, and no systematic association with a specific episode or a specific kind of shock (financial, oil, or monetary).

This suggests that the measure $\mathcal{S}_{i j, t}$ conflates two mechanisms: The international propagation of idiosyncratic shocks, $\mathcal{S}_{i j, t}^{\varepsilon}$, and the international equilibrium response to common shocks, $\mathcal{S}_{i j, t}^{\mathcal{F}}$. The former is a measure of synchronization in response to country-specific shocks; the latter is a measure of the dispersion in GDP growth rates in response to common shocks. This distinction complicates the estimated effect of financial integration on synchronization.

\subsection{The Effects of Finance on Synchronization}

The conventional panel regression that investigates the impact of financial integration on synchronization is due to KPP. It writes:

$$
\mathcal{S}_{i j, t}=\alpha_{i j}+\gamma_{t}+\beta \cdot K_{i j, t}+\delta \cdot Z_{i j, t}+\eta_{i j, t},
$$

where $K_{i j, t}$ measures bilateral financial linkages between $i$ and $j$, and $Z_{i j, t}$ denotes a vector of controls, for instance bilateral goods trade. The year effects $\gamma_{t}$ account for global shocks that affect all countries homogeneously. The country-pair specific effect $\alpha_{i j}$ ensures $\beta$ is estimated over time, in deviations from country-pair averages, which constitutes a substantial improvement relative to earlier estimations typically obtained in cross-section. See for instance Frankel and Rose (1998), Doyle and Faust (2005), Imbs (2006) or Baxter and Kouparitsas (2005), among many others. While estimates of $\beta$ are positive and significant in cross-section regressions, KPP show they switch signs and become significantly negative within country-pairs. Since the theory that underpins equation (8) models the propagation of shocks over time, the estimation should include country-pair fixed effects. The resulting negative 
estimates of $\beta$ are suggestive that financial integration exacerbates the asymmetry caused by country-specific shocks. This is the interpretation espoused by KPP.

This paper argues the existence of common shocks in equation (8) can affect the estimates of $\beta$. The previous section argues common shocks are mechanically embedded in $\mathcal{S}_{i j, t}$, provided they have heterogeneous country-specific effects. Consider now the possibility that common shocks also affect bilateral capital linkages. This is a well charted area. For instance Forbes and Warnock (2012) document that a key driving force of gross capital flows are changes in global risk. Rey (2013) argues capital flows worldwide obey global factors. Bruno and Shin (2014) document that changes in the VIX affect the cyclicality in capital flows worldwide. For simplicity, we posit a straightforward relation between capital cross-holdings and (common or idiosyncratic) shocks, i.e.:

$$
K_{i j, t}=a_{i j}^{K}+b_{i j}^{K} \mathcal{F}_{t}^{K}+\varepsilon_{i j, t}^{K} .
$$

This specification allows for permanent differences in capital cross-holdings, $a_{i j}^{K}$, for idiosyncratic shocks to bilateral capital $\varepsilon_{i j, t}^{K}$, and for a vector of common shocks $\mathcal{F}_{t}^{K}$. Common shocks can have heterogeneous consequences across country pairs, captured by $b_{i j}^{K}$. The specification is general, in that it can account for global cycles in financial integration, or for a potential trend in $K_{i j, t}$. If financial flows are procyclical (as in Kaminsky, Reinhart, and Vegh, 2005, Rey, 2013, Broner, Didier, Erce, and Schmukler, 2013, Bruno and Shin, 2015, for example), we should have $b_{i j}^{K} \geq 0$. If $K_{i j, t}$ displays an upward trend, $\mathcal{F}_{t}^{K}$ takes positive and rising values in $t$.

In order to bring into focus the role of common shocks, consider a version of equation (8) where the dependent variable is $\mathcal{S}_{i j, t}^{\mathcal{F}}$. The equation becomes:

$$
-\left|b_{i}^{y}-b_{j}^{y}\right| \cdot\left|\mathcal{F}_{t}^{y}\right|=\alpha_{i j}+\gamma_{t}+\beta^{\mathcal{F}} \cdot\left[a_{i j}^{K}+b_{i j}^{K} \mathcal{F}_{t}^{K}+\varepsilon_{i j, t}^{K}\right]+\delta \cdot Z_{i j, t}+\eta_{i j, t}^{\mathcal{F}} .
$$

where we used the fact that:

$$
\mathcal{S}_{i j, t}^{\mathcal{F}}=-\left|\left(b_{i}^{y}-b_{j}^{y}\right) \mathcal{F}_{t}^{y}\right|=-\left|b_{i}^{y}-b_{j}^{y}\right| \cdot\left|\mathcal{F}_{t}^{y}\right| .
$$

Clearly, the sign of $\beta^{\mathcal{F}}$ is given by:

$$
\operatorname{Cov}\left[-\left|b_{i}^{y}-b_{j}^{y}\right| \cdot\left|\mathcal{F}_{t}^{y}\right|, b_{i j}^{K} \mathcal{F}_{t}^{K}\right]=-\left|b_{i}^{y}-b_{j}^{y}\right| \cdot b_{i j}^{K} \operatorname{Cov}\left[\left|\mathcal{F}_{t}^{y}\right|, \mathcal{F}_{t}^{K}\right] .
$$


where $\operatorname{Cov}[\cdot]$ denotes the covariance operator. According to equation (12), a negative estimate of $\beta^{\mathcal{F}}$ requires, for example, a positive covariance between $\left|b_{i}^{y}-b_{j}^{y}\right|$ and $b_{i j}^{K}$ and a positive covariance between $\left|\mathcal{F}_{t}^{y}\right|$ and $\mathcal{F}_{t}^{K}$.

In what follows, we show that $\left|b_{i}^{y}-b_{j}^{y}\right|$ and $b_{i j}^{K}$ display a positive correlation in OECD data, i.e. GDP growth and capital flows happen to be responsive to common shocks in the same countries. One possible interpretation is that this finding arise because of the procyclicality of capital flows: Countries with elastic GDP are the systematic destination of capital flows during global (or regional) booms, but their source in global (or regional) recessions. We show that this pattern holds in our data. We also show that $\left|\mathcal{F}_{t}^{y}\right|$ and $\mathcal{F}_{t}^{K}$ correlate positively, which in turn implies that $\mathcal{F}_{t}^{y}$ and $\mathcal{F}_{t}^{K}$ do not correlate perfectly. ${ }^{9}$ In our data, $\operatorname{Cov}\left[\left|\mathcal{F}_{t}^{y}\right|, \mathcal{F}_{t}^{K}\right]$ ranges from 0.20 to 0.50 .

We emphasize these results are driven by permanent features of GDP growth and of capital flows, that prevail systematically in response to common shocks. They reflect the fact that permanent differences exist across countries in terms of how GDP growth and capital flows respond to common shocks. But they are silent on the response of financial flows to country-specific developments, and its consequence on synchronization. The issues just discussed are absent when the measure of synchronization is conditioned on idiosyncratic shocks. By definition, idiosyncratic shocks do not display any permanent cross-sectional pattern, and therefore $\mathcal{S}_{i j, t}^{\varepsilon}=-\left|\varepsilon_{i, t}^{y}-\varepsilon_{j, t}^{y}\right|$ cannot correlate systematically with $b_{i j}^{K}$.

\section{Results}

This Section first introduces the various data sources that have now become standard in this literature. It then moves to a description of the paper's key results.

\subsection{Data}

Annual data on GDP at constant prices are collected from the OECD National Accounts. GDP is measured using the expenditure approach, and deflated with each country's GDP deflator. Bilateral financial linkages are obtained from the

\footnotetext{
${ }^{9}$ If $\mathcal{F}_{t}^{y}$ and $\mathcal{F}_{t}^{K}$ were perfectly correlated, then $\operatorname{cov}\left[\left|\mathcal{F}_{t}^{y}\right|, \mathcal{F}_{t}^{K}\right]$ would be zero.
} 
"International Locational Banking Statistics" released by the Bank for International Settlements (BIS). The data collect information on international financial claims and liabilities of banks resident in a BIS reporting country, vis-a-vis counterparty countries. The data are in USD, and deflated using the US GDP deflator. They focus on bank linkages, and are therefore of somewhat limited scope. But few alternatives exist that measure bilateral financial linkages over time for other classes of assets. The only option are the surveys collected by the International Monetary Fund as part of the Coordinated Portfolio Investment Survey, which collect information on all classes of financial assets. But the time coverage is limited to the 2000's, and is very sparse for the early years.

Data coverage is best for reporting countries, which include most developed economies. It is much more incomplete for counterparty countries that include many developing economies, where a lot of data points are missing. The practice has been to combine information about claims and liabilities in both directions. For instance, information on liabilities due by counterparty country $j$ towards country $i$ is completed by data on claims held by reporting country $i$ in country $j$. In addition, given the recent globalization in financial flows, the data are normalized, by population or GDP. In particular, consider two measures for $K_{i j, t}$ :

$K_{i j, t}^{p o p}=\frac{1}{4}\left[\ln \left(\frac{A_{i j, t}}{P_{i, t}+P_{j, t}}\right)+\ln \left(\frac{L_{i j, t}}{P_{i, t}+P_{j, t}}\right)+\ln \left(\frac{A_{j i, t}}{P_{i, t}+P_{j, t}}\right)+\ln \left(\frac{L_{j i, t}}{P_{i, t}+P_{j, t}}\right)\right]$,

and:

$K_{i j, t}^{g d p}=\frac{1}{4}\left[\ln \left(\frac{A_{i j, t}}{Y_{i, t}+Y_{j, t}}\right)+\ln \left(\frac{L_{i j, t}}{Y_{i, t}+Y_{j, t}}\right)+\ln \left(\frac{A_{j i, t}}{Y_{i, t}+Y_{j, t}}\right)+\ln \left(\frac{L_{j i, t}}{Y_{i, t}+Y_{j, t}}\right)\right]$,

where $A_{i j, t}\left(L_{i j, t}\right)$ denotes the claims (liabilities) on country $j$ held by banks located in country $i, Y_{i, t}$ is GDP in country $i$ and time $t$, and $P_{i, t}$ is population in country $i$ at time $t$. Both measures are bilateral; they contain no information on the direction of capital holdings. Figure 3 reports the average value of $K_{i j, t}^{p o p}$ and $K_{i j, t}^{g d p}$ across country pairs. Even though both variables are normalized, an upward trend clearly survives in both measures.

Bilateral goods trade data are collected from the IMF's Direction of Trade data set. The data are expressed in USD, and deflated using the US GDP deflator. Trade intensity is measured as the ratio of bilateral exports and imports, as a proportion 
of total trade in each country, following Frankel and Rose (1998), among many others. As in KPP, data are limited to 18 developed economies, in order to minimize structural differences in the cross section. ${ }^{10}$ The sample is initially focused on the recent period with data until 2012, but later restricted to the "tranquil" times that preceded 2006.

Figure 3 The Evolution Of Banking Integration

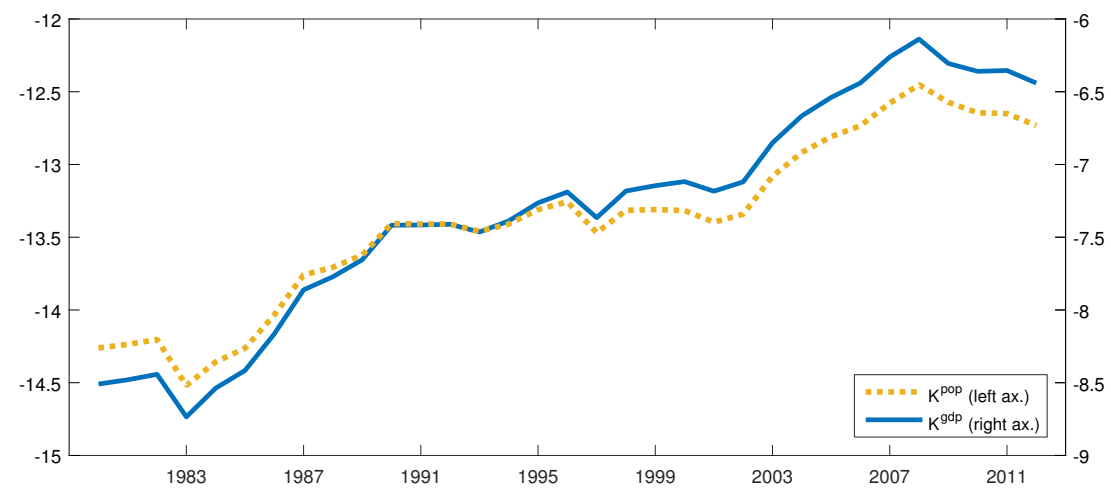

Note. The solid and dotted lines plot the evolution over time of the average value of $K_{i j, t}^{p o p}$ and $K_{i j, t}^{g d p}$ for the 1980-2012 period. The average is computed across 153 country pairs (our sample spans 18 countries) for each year.

The key argument of the paper rests on the identification of shocks to GDP that are common across countries. The decomposition is performed in as simple a manner as possible, using simple factor analysis. In particular, we estimate:

$$
y_{i, t}=a_{i}^{y}+b_{1, i}^{y} \mathcal{F}_{1, t}^{y}+\ldots+b_{n, i}^{y} \mathcal{F}_{n, t}^{y}+\nu_{i t}^{y},
$$

where $n$ is the number of countries in the sample. The vector of $n$ factors provides an exact decomposition of the variance in the dependent variable, but since each loading is estimated with error, an estimation residual $\nu_{i t}^{y}$ appears in both regressions. Denoting fitted values with a hat, the decomposition can be rewritten as:

$$
y_{i t}=\hat{a}_{i}+\hat{b}_{1, i}^{y} \hat{\mathcal{F}}_{1, t}^{y}+\ldots+\hat{b}_{n, i}^{y} \hat{\mathcal{F}}_{n, t}^{y} .
$$

\footnotetext{
${ }^{10}$ The 18 countries are: Australia, Austria, Belgium, Canada, Switzerland, Germany, Denmark, Spain, Finland, France, the UK, Ireland, Italy, Japan, the Netherlands, Portugal, Sweden, and the US. Duval, Li, Saraf, and Seneviratne (2016) examine a dataset including 63 advanced and emerging countries between 1995 and 2013, focusing on the role of (value added) trade in synchronizing business cycles.
} 
The decomposition defines factors that may or may not be common to two or more countries. A conventional approach to distinguish common from idiosyncratic factors is to consider the eigenvalues associated with each factor: Idiosyncratic shocks display eigenvalues strictly below one, while they are above one for shocks that affect two countries or more. Since by construction, the eigenvalues associated with $\hat{\mathcal{F}}_{k, t}^{y}$ decrease in $k$, this provides a decomposition of factors into ones that are common to two countries or more, and ones that are specific to one single economy.

Table 1 provides a summary of the factor estimates for GDP growth rates $y_{i t}$. Two factors are enough to explain almost three-quarters of the variance in GDP growth. This is not surprising: It is simply a reformulation of well known facts in the framework of a simple factor analysis, established for instance by Kose, Otrok, and Whiteman (2003) for GDP growth rates.

Table 1 Factor Estimates For GDP Growth

\begin{tabular}{rrrr}
\hline & Eigenvalues & $\begin{array}{r}\text { Share of } \\
\text { variance }\end{array}$ & $\begin{array}{r}\text { Cum. share } \\
\text { of variance }\end{array}$ \\
\hline $\mathcal{F}_{1}$ & 10.67 & 0.59 & $59 \%$ \\
$\mathcal{F}_{2}$ & 2.21 & 0.12 & $72 \%$ \\
$\mathcal{F}_{3}$ & 1.02 & 0.06 & $77 \%$ \\
$\mathcal{F}_{4}$ & 0.89 & 0.05 & $82 \%$ \\
$\mathcal{F}_{5}$ & 0.83 & 0.05 & $87 \%$ \\
\hline
\end{tabular}

Note. Principal components are computed on the panel of 18 GDP growth series $\left(y_{i t}\right)$ over the sample period 1980-2012.

Table 1 also implies a decomposition of $y_{i t}$ into common vs. country-specific shocks, according to the estimated eigenvalue associated with each factor. Using Section 2's notation, the first column of Table 1 implies the following decomposition:

$$
y_{i t}=\hat{a}_{i}+\hat{b}_{1, i}^{y} \hat{\mathcal{F}}_{1, t}^{y}+\hat{b}_{2, i}^{y} \hat{\mathcal{F}}_{2, t}^{y}+\hat{b}_{3, i}^{y} \hat{\mathcal{F}}_{3, t}^{y}+\hat{\varepsilon}_{i, t}^{y},
$$

The first three principal components are common to two countries or more. ${ }^{11}$

\footnotetext{
${ }^{11}$ See Appendix A2 for a summary description of the estimated common factors.
} 


\subsection{Estimation results}

Equation (8) is the paper's key panel regression. We use the principal component decomposition just described to run three versions of the estimation. The first simply reproduces known results, where the dependent variable is given by $\mathcal{S}_{i j, t}$ that embeds both common and idiosyncratic shocks. The two alternative specifications condition the estimation on one kind of shock only: On common shocks only, with $\mathcal{S}_{i j, t}^{\mathcal{F}}$ as the dependent variable, and on idiosyncratic shocks only, with $\mathcal{S}_{i j, t}^{\varepsilon}$ as the dependent variable. All three estimations are performed for the two variants of $K_{i j, t}$, normalized by population or by GDP.

Table 2 abstracts from country-pair fixed effects, and estimates $\beta$ on the crosssectional dimension of the data, between country pairs.

Table 2 Banking Integration and Business Cycle Synchronization: Cross-sectional ("Between") Estimates

\begin{tabular}{lrrrrrr}
\hline & $\mathcal{S}$ & $\mathcal{S}^{\mathcal{F}}$ & \multicolumn{1}{c}{$\mathcal{S}^{\varepsilon}$} & \multicolumn{1}{c}{$\mathcal{S}$} & $\mathcal{S}^{\mathcal{F}}$ & $\mathcal{S}^{\varepsilon}$ \\
\hline & \multicolumn{1}{c}{$(1)$} & \multicolumn{1}{c}{$(2)$} & \multicolumn{1}{c}{$(3)$} & \multicolumn{1}{c}{$(4)$} & \multicolumn{1}{c}{$(5)$} & $(6)$ \\
\hline Banking / Pop. $\left(K^{\text {pop }}\right)$ & 0.095 & 0.106 & 0.038 & & & \\
& $(0.011)$ & $(0.008)$ & $(0.007)$ & & & \\
Banking / GDP $\left(K^{g d p}\right)$ & {$[8.70]$} & {$[12.85]$} & {$[5.43]$} & & & \\
& & & & 0.091 & 0.082 & 0.049 \\
& & & & $(0.010)$ & $(0.007)$ & $(0.006)$ \\
Observations & 4863 & 4863 & 4863 & 4863 & 4863 & 4863 \\
$R^{2}$ & 0.092 & 0.176 & 0.121 & 0.095 & 0.170 & 0.127 \\
Country Pairs & 153 & 153 & 153 & 153 & 153 & 153 \\
\hline
\end{tabular}

Note. All regression specifications include a vector of year fixed effects. Estimation is performed over the 1980-2012 period.

The estimates are systematically positive, confirming the positive association between finance and synchronization on average. As argued by KPP, caution is in order in interpreting this result if there exist permanent reasons why country pairs display high cycle synchronization and high financial integration, such as the practice of a common language, geographic proximity, or common institutions. Hence allowances for country pair effects, $\alpha_{i j}$, are of the essence. 
Table 3 reports the panel estimates of equation (8) allowing for fixed effects. Table 4 includes a control for the intensity of bilateral trade. In both tables, columns (1) and (4) reproduce the significantly negative estimates of $\beta$ within country pair, as in KPP. There are permanent reasons why financial links are intense between synchronized economies, captured by $\alpha_{i j}$ in equation (8); but once these are accounted for, a change in financial integration tends to be associated with lower values of $\mathcal{S}_{i j, t} \cdot{ }^{12}$

Table 3 Banking Integration and Business Cycle Synchronization: Panel ("Within") Estimates

\begin{tabular}{lccrrrr}
\hline & $\mathcal{S}$ & $\mathcal{S}^{\mathcal{F}}$ & \multicolumn{1}{c}{$\mathcal{S}^{\varepsilon}$} & \multicolumn{1}{c}{$\mathcal{S}$} & $\mathcal{S}^{\mathcal{F}}$ & $\mathcal{S}^{\varepsilon}$ \\
\hline & \multicolumn{1}{c}{$(1)$} & \multicolumn{1}{c}{$(2)$} & \multicolumn{1}{c}{$(3)$} & \multicolumn{1}{c}{$(4)$} & \multicolumn{1}{c}{$(5)$} & $(6)$ \\
\hline Banking / Pop. $\left(K^{p o p}\right)$ & -0.144 & -0.154 & 0.075 & & & \\
& $(0.040)$ & $(0.030)$ & $(0.021)$ & & & \\
Banking / GDP $\left(K^{g d p}\right)$ & {$[-3.63]$} & {$[-5.05]$} & {$[3.54]$} & & & \\
& & & & -0.148 & -0.159 & 0.072 \\
& & & & $(0.042)$ & $(0.032)$ & $(0.022)$ \\
Observations & 4863 & 4863 & 4863 & 4863 & 4863 & 4863 \\
$R^{2}$ & 0.099 & 0.222 & 0.133 & 0.099 & 0.222 & 0.133 \\
Country Pairs & 153 & 153 & 153 & 153 & 153 & 153 \\
\hline
\end{tabular}

Note. All regression specifications include a vector of country-pair fixed effects and a vector of year fixed effects. Estimation is performed over the 1980-2012 period. Standard errors are adjusted for country-pair-level heteroskedasticity and autocorrelation.

However, as this paper has argued, $\mathcal{S}_{i j, t}$ embeds the heterogeneous responses of GDP to common shocks. Inasmuch as common shocks also affect $K_{i j, t}$, negative estimates of $\beta$ in columns (1) and (4) could still arise because of features specific to each country pair: The responses of $\mathcal{S}_{i j, t}$ and $K_{i j, t}$ to common shocks. Columns (2) and (5) in both tables confirm that negative estimates of $\beta$ arise when synchronization is conditioned on common shocks only, as in equation (10). As argued in Section 2 , this result could be driven by a systematic correlation between $b_{i}^{y}-b_{j}^{y}$ and $b_{i j}^{K}$.

Columns (3) and (6) of Tables 3 and 4 show that the estimates of $\beta$ are significantly positive when synchronization is measured by $\mathcal{S}_{i j, t}^{\varepsilon}$ as in equation (6). The

\footnotetext{
${ }^{12}$ Estimates of $\beta$ continue to be significantly negative if the dependent variable is $\mathcal{S}_{i j, t}^{\mathcal{F}}+\mathcal{S}_{i j, t}^{\varepsilon}$ instead of $\mathcal{S}_{i j, t}$. These results are available upon request.
} 
Table 4 Banking Integration and Business CyCle Synchronization: Panel ("Within") Estimates With Controls

\begin{tabular}{|c|c|c|c|c|c|c|}
\hline & $\mathcal{S}$ & $\mathcal{S}^{\mathcal{F}}$ & $\mathcal{S}^{\varepsilon}$ & $\mathcal{S}$ & $\mathcal{S}^{\mathcal{F}}$ & $\mathcal{S}^{\varepsilon}$ \\
\hline & (1) & $(2)$ & (3) & (4) & $(5)$ & (6) \\
\hline Banking / Pop. $\left(K^{p o p}\right)$ & $\begin{array}{r}-0.102 \\
(0.040) \\
{[-2.57]}\end{array}$ & $\begin{array}{c}-0.132 \\
(0.028) \\
{[-4.71]}\end{array}$ & $\begin{array}{r}0.060 \\
(0.024) \\
{[2.55]}\end{array}$ & & & \\
\hline Banking / GDP $\left(K^{g d p}\right)$ & & & & $\begin{array}{c}-0.106 \\
(0.041) \\
{[-2.55]}\end{array}$ & $\begin{array}{c}-0.137 \\
(0.029) \\
{[-4.65]}\end{array}$ & $\begin{array}{r}0.056 \\
(0.024) \\
{[2.32]}\end{array}$ \\
\hline Trade & $\begin{array}{r}-0.382 \\
(0.134) \\
{[-2.86]}\end{array}$ & $\begin{array}{r}-0.198 \\
(0.114) \\
{[-1.75]}\end{array}$ & $\begin{array}{r}0.132 \\
(0.078) \\
{[1.69]} \\
\end{array}$ & $\begin{array}{c}-0.386 \\
(0.133) \\
{[-2.90]} \\
\end{array}$ & $\begin{array}{c}-0.203 \\
(0.113) \\
{[-1.79]}\end{array}$ & $\begin{array}{r}0.141 \\
(0.078) \\
{[1.81]}\end{array}$ \\
\hline Observations & 4859 & 4859 & 4859 & 4859 & 4859 & 4859 \\
\hline$R^{2}$ & 0.103 & 0.224 & 0.134 & 0.103 & 0.225 & 0.134 \\
\hline Country Pairs & 153 & 153 & 153 & 153 & 153 & 153 \\
\hline
\end{tabular}

Note. All regression specifications include a vector of country-pair fixed effects and a vector of year fixed effects. Estimation is performed over the 1980-2012 period. Standard errors are adjusted for country-pair-level heteroskedasticity and autocorrelation.

synchronization measure captures the equilibrium response of GDP in countries $i$ and $j$ to a country-specific shock: This is the object that models of the international business cycle have ambiguous predictions about. The contagious consequences of finance mirrored by positive estimates of $\beta$ are consistent with models where financial flows serve to alleviate binding constraints, rather than to chase high returns.

In the previous Section we showed analytically that negative estimates of $\beta$ and $\beta^{\mathcal{F}}$ arise when the elasticities of GDP and capital to common shocks are systematically related. This means that high $b_{i}^{y}$ countries should also display high $b_{i j}^{K}$. Figure 4 plots the estimates of $\hat{b}_{1, i}^{y}$ against $\hat{b}_{1, i}^{K}$, where $\hat{b}_{1, i}^{K}$ is the first factor loading of country $i$ 's capital, computed as $K_{i, t}=\sum_{j} K_{i j, t}$. The correlation is positive and significant, with inelastic countries on both counts like Australia, Japan, and Portugal, and elastic countries on both counts, like the US and most of continental Europe. $^{13}$

\footnotetext{
${ }^{13}$ Elasticities of GDP correlate negatively with a measure of remoteness: $b_{i}^{y}$ tend to take significantly lower values for countries that are far from the gravity center of world trade, a measure borrowed from Bravo-Ortega and di Giovanni (2006). The coefficient estimate is -1.14, with a t-statistic of -4.00 .
} 
Figure 4 Correlation Between Factor Loadings On GDP And CAPITAL

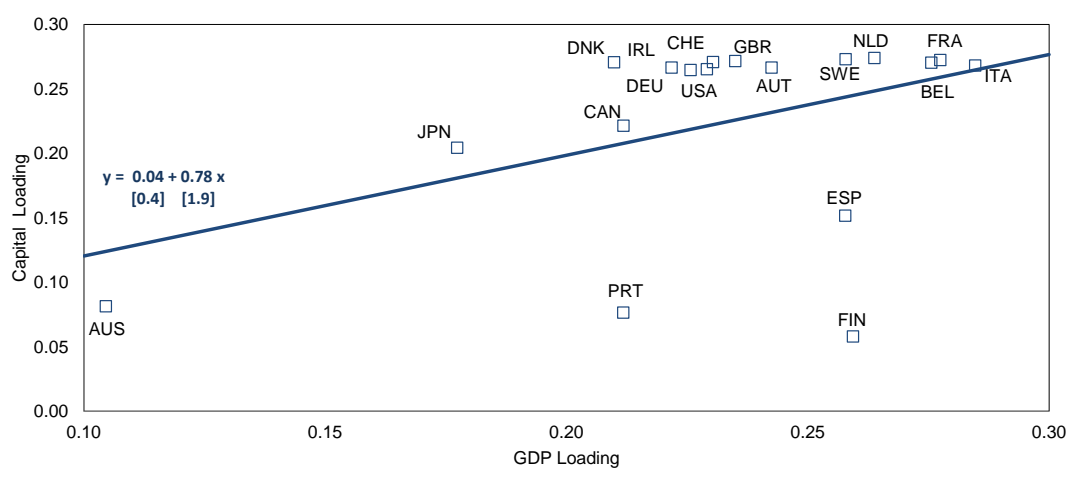

Note. On the horizontal axis is the loading on GDP $\left(\hat{b}_{1, i}^{y}\right)$. On the vertical axis is the loading on capital $\hat{b}_{1, i}^{K}$, where $\hat{b}_{1, i}^{K}$ is the first factor loading of country $i$ 's capital, computed as $K_{i, t}=\sum_{j} K_{i j, t}$. The slope and the constant of the fitted line are reported together with t-statistics in square brackets.

One possible interpretation of such a positive correlation between $\hat{b}_{1, i}^{y}$ and $\hat{b}_{1, i}^{K}$ is that capital should go from countries with inelastic GDP to countries with elastic GDP in periods of global (or regional) booms, and the other way round for negative common shocks. That is: Capital flows are procyclical, as it is well documented in the literature (see, among others, Kaminsky, Reinhart, and Vegh, 2005, Rey, 2013, Broner, Didier, Erce, and Schmukler, 2013, Bruno and Shin, 2015).. This would account for the positive correlation between GDP and capital loadings in Figure 4.

Figure 5 explores the empirical validity of this interpretation by plotting the cross-section of $\hat{b}_{1, i}^{y}$ against measures of the changes in net bank holdings as per the BIS data. We compute the average change in net bank holdings, computed for positive or negative values of $\mathcal{F}_{t}^{y}$. Define:

$$
\operatorname{KNET}_{i}^{+}=\sum_{\mathcal{F}_{t}^{y}>0} \Delta_{t}\left[\sum_{j} \ln \left(A_{j i, t}+L_{i j, t}\right)-\ln \left(A_{i j, t}+L_{j i, t}\right)\right]
$$

and:

$$
K N E T_{i}^{-}=\sum_{\mathcal{F}_{t}^{y}<0} \Delta_{t}\left[\sum_{j} \ln \left(A_{j i, t}+L_{i j, t}\right)-\ln \left(A_{i j, t}+L_{j i, t}\right)\right]
$$


where $\Delta_{t}[X]$ denotes the first difference of variable $X$.

Panel (a) of Figure 5 plots the estimates of $\hat{b}_{1, i}^{y}$ against the average change in net bank holdings computed for positive values of $\mathcal{F}_{t}^{y}$ (i.e., $K N E T_{i}^{+}$).

Figure 5 Correlation Between loadings On GDP And Average Changes In Net BANK Holdings
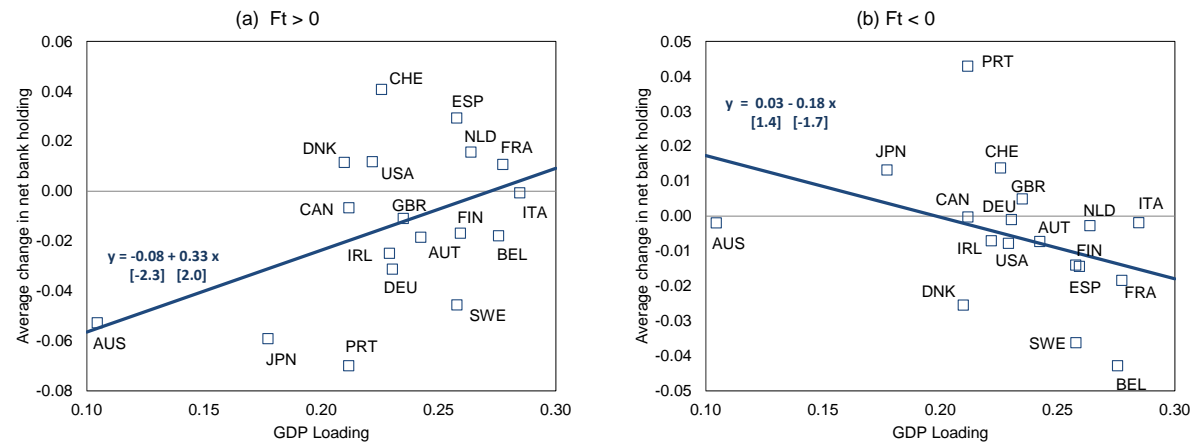

Note. On the horizontal axis is the loading on GDP $\left(\hat{b}_{1, i}^{y}\right)$. On the vertical axis is the change in net bank holdings averaged over periods when $\mathcal{F}_{t}>0\left(K N E T_{i}^{+}\right)$, in panel (a); and when $\mathcal{F}_{t}<0\left(K N E T_{i}^{-}\right)$, in panel (b). The slope and the constant of the fitted line are reported together with t-statistics in square brackets.

A significantly positive correlation exists, which means that on average net capital increases in countries whose GDP is responsive to common shocks in times of global (or regional) booms. Panel (b) of Figure 5 plots the estimates of $\hat{b}_{1, i}^{y}$ against $K N E T_{i}^{-}$. A negative relation exists, though it is only weakly significant. There is some tendency for net capital to fall in countries with elastic GDP in times of global (or regional) recessions, but it is less clear cut than the opposite in booms. Taken together, Figure 5 suggests that (bank) capital tends to flow between countries with different loadings on GDP: From low $\hat{b}_{i}^{y}$ to high $\hat{b}_{j}^{y}$ in times of booms, and, to a smaller extent, the opposite in times of recessions. This drives a systematic correlation between $\hat{b}_{1, i}^{y}$ and $\hat{b}_{1, i}^{K}$, creates negative estimates of $\beta^{\mathcal{F}}$, and ultimately of $\beta$. But this tends to always happen between the same countries. ${ }^{14}$

\footnotetext{
${ }^{14}$ Of course, all the results here depend on the empirical heterogeneity in $b_{i}^{y}$ and $b_{i}^{K}$, and their empirical correlation across countries. Nothing guarantees that what this paper uncovers should hold universally. For instance, Morgan, Rime, and Strahan (2004) find estimates of $\beta$ are positive in a similar estimation performed across US states between 1976 and 1994. That could reflect the relative homogeneity of US States, so that $\mathcal{S}_{i j, t}^{\varepsilon}$ is well captured by $\mathcal{S}_{i j, t}$. A contrario, the negative
} 
The panel of GDP growth rates used until now include the Great Recession years, until 2012. Arguably, the most recent period includes years when financial linkages may have been especially contagious. For instance Kalemli-Ozcan, Papaioannou, and Perri (2013) show that estimates of $\beta$ become less negative if the crisis years are included. They explain the instability in coefficient estimates with the prevalence of credit shocks during the Great Recession. Given the magnitude and globality of the Great Recession, it is likely to affect estimates of common shocks, and thus the estimated elasticities of GDP and capital to common shocks.

Table 5 repeats the previous three estimations, but on a sample that now stops in $2006 .{ }^{15}$ Estimates of $\beta$ continue to be negative when the dependent variable is $\mathcal{S}_{i j, t}$ or $\mathcal{S}_{i j, t}^{\mathcal{F}}$; and to be positive when it is $\mathcal{S}_{i j, t}^{\varepsilon}$, consistent with the prevalence of contagious shocks, and perhaps of credit constraints, in the years preceding the Great Recession.

Table 5 Banking Integration and Business Cycle Synchronization: Panel ("Within") Estimates Excluding The Great Recession Years

\begin{tabular}{|c|c|c|c|c|c|c|}
\hline & $\mathcal{S}$ & $\mathcal{S}^{\mathcal{F}}$ & $\mathcal{S}^{\varepsilon}$ & $\mathcal{S}$ & $\mathcal{S}^{\mathcal{F}}$ & $\mathcal{S}^{\varepsilon}$ \\
\hline & (1) & $(2)$ & $(3)$ & $(4)$ & $(5)$ & (6) \\
\hline Banking / Pop. $\left(K^{p o p}\right)$ & $\begin{array}{c}-0.280 \\
(0.063) \\
{[-4.46]}\end{array}$ & $\begin{array}{c}-0.314 \\
(0.052) \\
{[-6.04]}\end{array}$ & $\begin{array}{r}0.091 \\
(0.028) \\
{[3.22]}\end{array}$ & & & \\
\hline Banking / GDP $\left(K^{g d p}\right)$ & & & & $\begin{array}{r}-0.284 \\
(0.066) \\
{[-4.33]} \\
\end{array}$ & $\begin{array}{r}-0.321 \\
(0.054) \\
{[-5.91]} \\
\end{array}$ & $\begin{array}{r}0.085 \\
(0.029) \\
{[2.91]}\end{array}$ \\
\hline Observations & 3945 & 3945 & 3945 & 3945 & 3945 & 3945 \\
\hline$R^{2}$ & 0.118 & 0.183 & 0.102 & 0.118 & 0.181 & 0.102 \\
\hline Country Pairs & 153 & 153 & 153 & 153 & 153 & 153 \\
\hline
\end{tabular}

Note. All regression specifications include a vector of country-pair fixed effects and a vector of year fixed effects. Estimation is performed over the 1980-2006 period. Standard errors are adjusted for country-pair-level heteroskedasticity and autocorrelation.

Endogeneity is an obvious concern for OLS estimates of equation (8). There is every reason to expect that financial linkages, especially bank linkages, are governed by a diversification motive. Then $K_{i j, t}$ tends to take high values between countries estimates of $\beta$ in Duval, Li, Saraf, and Seneviratne (2016) could arise from the large heterogeneity in a sample formed by 63 countries at various levels of development.

${ }^{15}$ Appendix A3 provides the detailed factor estimates for the 1980-2006 sample. 
that are out of sync, i.e., where $\mathcal{S}_{i j, t}$ takes large negative values. This endogeneity bias results in estimates of $\beta$ that are biased downwards: Negative OLS estimates in columns (1)-(2) and (3)-(5) are biased away from zero, and positive OLS estimates in columns (3) and (6) are biased towards zero.

An important contribution of KPP is the introduction of an instrument for $K_{i j, t}$ that is time-varying, and country pair specific. The instrument builds from the existence of European directives, issued by the European Commission at a certain date, and implemented later in member countries, with lags that vary with each country. KPP focus on the 27 directives that pertain to financial regulation, as part of the Financial Services Action Plan launched in 1998 to remove barriers across Europe. At each point in time, and for each country pair they consider the overlap in directives that happen to be implemented in both countries $i$ and $j$. They argue implementation dates are exogenous to current economic conditions, so that the instrument satisfies standard excludability constraints. The index constitutes a novel and powerful instrument for financial integration $K_{i j, t}{ }^{16}$

Table 6 Banking Integration and Business Cycle Synchronization: Panel ("Within") IV Estimates Excluding The Great Recession Years

\begin{tabular}{|c|c|c|c|c|c|c|}
\hline & $\mathcal{S}$ & $\mathcal{S}^{\mathcal{F}}$ & $\mathcal{S}^{\varepsilon}$ & $\mathcal{S}$ & $\mathcal{S}^{\mathcal{F}}$ & $\mathcal{S}^{\varepsilon}$ \\
\hline & (1) & (2) & $(3)$ & (4) & $(5)$ & (6) \\
\hline Banking / Pop. $\left(K^{p o p}\right)$ & $\begin{array}{c}-0.487 \\
(0.132) \\
{[-3.69]}\end{array}$ & $\begin{array}{c}-0.367 \\
(0.084) \\
{[-4.35]}\end{array}$ & $\begin{array}{r}0.237 \\
(0.089) \\
{[2.66]}\end{array}$ & & & \\
\hline Banking / GDP $\left(K^{g d p}\right)$ & & & & $\begin{array}{c}-0.519 \\
(0.141) \\
{[-3.69]}\end{array}$ & $\begin{array}{c}-0.391 \\
(0.090) \\
{[-4.35]}\end{array}$ & $\begin{array}{r}0.253 \\
(0.095) \\
{[2.66]}\end{array}$ \\
\hline Observations & 3951 & 3951 & 3951 & 3951 & 3951 & 3951 \\
\hline$R^{2}$ & 0.112 & 0.188 & 0.054 & 0.110 & 0.185 & 0.046 \\
\hline Country Pairs & 153 & 153 & 153 & 153 & 153 & 153 \\
\hline
\end{tabular}

Note. All regression specifications include a vector of country-pair fixed effects and a vector of year fixed effects. Estimation is performed over the 1980-2006 period. Standard errors are adjusted for country-pair-level heteroskedasticity and autocorrelation.

Table 6 presents Instrumental Variable estimations of equation (8), once again for the three considered measures of cycle synchronization, $\mathcal{S}_{i j, t}, \mathcal{S}_{i j, t}^{\mathcal{F}}$, and $\mathcal{S}_{i j, t}^{\varepsilon}$.

\footnotetext{
${ }^{16}$ Following KPP, the instrument takes value zero for non EU member countries, and for all years before 1998 .
} 
Estimates of $\beta$ are still significantly negative for the measures of synchronization that embed common shocks, $\mathcal{S}_{i j, t}$ and $\mathcal{S}_{i j, t}^{\mathcal{F}}$. As in Table 5 , when synchronization focuses on idiosyncratic shocks (i.e., when using $\mathcal{S}_{i j, t}^{\varepsilon}$ as a dependent variable) estimates of $\beta$ are positive and significant.

\section{Extensions}

This Section discusses two extensions to our baseline specification. First, we consider an alternative measure of synchronization, namely the Pearson correlation coefficient. Second, we consider the possibility that our estimated factor loadings vary over time.

\subsection{Correlation Coefficients}

The measure of cycle synchronization used in most of the literature until recently is the Pearson correlation coefficient. It is problematic in panel regressions, because it is measured with error and because it responds to changes in the variance of the underlying shocks. Still, KPP show that the negative estimates in equation (8) survive this alternative measurement of synchronization.

Consider the consequences of equation (4) on the Pearson correlation $\rho_{i j}$ between the GDP growth rates of countries $i$ and $j$. By definition:

$$
\rho_{i j}=\left(w_{i}^{\mathcal{F}}\right)^{\frac{1}{2}}\left(w_{j}^{\mathcal{F}}\right)^{\frac{1}{2}}+\left(1-w_{i}^{\mathcal{F}}\right)^{\frac{1}{2}}\left(1-w_{j}^{\mathcal{F}}\right)^{\frac{1}{2}} \rho_{i j}^{\varepsilon},
$$

where $w_{i}^{\mathcal{F}}=\frac{b_{i}^{2} V\left(\mathcal{F}_{t}^{y}\right)}{V\left(y_{i, t}\right)}$ is the share of the variance of GDP growth in country $i$ that corresponds to common shocks, and $\rho_{i j}^{\epsilon}$ is the Pearson correlation coefficient that captures cycle synchronization conditional on idiosyncratic shocks. As is evident, in the presence of common shocks, the Pearson correlation between GDP growth is an imperfect measure of the actual correlation coefficient implied by country-specific shocks, even if underlying risk is held constant. A corrective term drives a wedge between the two coefficients. Its magnitude depends on the share of the variance in GDP growth that can be explained by common shocks in both countries $i$ and $j$.

Correlation coefficients were traditionally used in cross-section, since they are computed in the time dimension. But it is also possible to compute them over 
successive sub-periods, and use the resulting panel as the dependent variable in equation (8). Then the corrective term in equation (20) involving $w_{i}^{\mathcal{F}}$ and $w_{j}^{\mathcal{F}}$ can also be time-varying. With an intuition that is analogous to Forbes and Rigobon (2002), changes in the variance of the underlying shocks affect the panel properties of $\rho_{i j}$. The empirical question posed by this possibility is whether the estimates of $\beta$ in equation (8) depend on how synchronization is measured, by $\rho_{i j}$ or by $\rho_{i j}^{\varepsilon}$.

Table 7 shows that it does: the estimates of $\beta$ are negative and borderline significant in columns (1) and (4), when the dependent variable in equation (8) is given by $\rho_{i j, t}$, computed over five-year windows. It becomes strongly negative and significant when the correlation coefficient is computed on common shocks only, in columns (2) and (5). But it is essentially zero when the dependent variable is replaced by $\rho_{i j, t}^{\varepsilon}$. We note that Pearson correlation coefficients are estimated over five-year windows in table 7 , and constitute therefore measures of synchronization that are estimated with considerable error. We note furthermore that changes over time in both $\rho_{i j, t}$ and $\rho_{i j, t}^{\varepsilon}$ continue to be affected by changes in the variances of the underlying shocks. While it is reassuring that the Pearson correlation coefficient conditioned on common shocks continues to be negatively related with financial integration, it is not overly worrisome that the relation between $\rho_{i j, t}^{\varepsilon}$ and financial integration is essentially zero: There are many well known reasons why this may happen.

Table 7 Banking Integration and Business Cycle Synchronization: Panel ("Within") Estimates - Pearson Correlation Coefficient

\begin{tabular}{lcccccr}
\hline & $\rho$ & $\rho^{\mathcal{F}}$ & $\rho^{\varepsilon}$ & $\rho$ & $\rho^{\mathcal{F}}$ & $\rho^{\varepsilon}$ \\
\hline & \multicolumn{1}{c}{$(1)$} & \multicolumn{1}{c}{$(2)$} & \multicolumn{1}{c}{$(3)$} & \multicolumn{1}{c}{$(4)$} & \multicolumn{1}{c}{$(5)$} & $(6)$ \\
\hline Banking / Pop. (K $\left.{ }^{p o p}\right)$ & -0.102 & -0.031 & -0.017 & & & \\
& $(0.061)$ & $(0.015)$ & $(0.020)$ & & & \\
Banking / GDP $\left(K^{g d p}\right)$ & {$[-1.67]$} & {$[-2.07]$} & {$[-0.83]$} & & & \\
& & & & -0.110 & -0.033 & -0.018 \\
& & & & $(0.064)$ & $(0.016)$ & $(0.021)$ \\
Observations & 915 & 915 & 915 & 915 & 915 & 915 \\
$R^{2}$ & 0.122 & 0.259 & 0.001 & 0.123 & 0.260 & 0.001 \\
Country Pairs & 153 & 153 & 153 & 153 & 153 & 153 \\
\hline
\end{tabular}

Note. All regression specifications include a vector of country-pair fixed effects and a vector of year fixed effects. Estimation is performed over the 1980-2012 period. Standard errors are adjusted for country-pair-level heteroskedasticity and autocorrelation. 


\subsection{Time-Varying Factor Loadings}

During the estimation period we consider (1980-2012) global goods and financial markets have grown at fast pace as countries integrated. One would think the responsiveness of countries to global developments is likely to have changed, as well. In this Section we address this possibility, by estimating a model where countryspecific factor loadings are allowed to vary over time.

Consider a version of equation (4) where factor loadings are allowed to be timevarying:

$$
y_{t}=a_{t}^{y}+b_{t}^{y} \mathcal{F}_{t}^{y}+e_{t}^{y},
$$

where, for ease of notation, the country subscripts $i$ are ignored. Assume that the coefficients $a_{t}^{y}$ and $b_{t}^{y}$ evolve as random walks. In state-space form this model can be expressed as:

$$
\begin{aligned}
y_{t} & =\mathbf{X}_{t} \boldsymbol{\beta}_{t}+e_{t}^{y} . \\
\boldsymbol{\beta}_{t} & =\boldsymbol{\beta}_{t-1}+v_{t}
\end{aligned}
$$

where $\mathbf{X}_{t}=\left(1, \mathcal{F}_{t}^{y}\right), \boldsymbol{\beta}_{t}=\left(a_{t}^{y}, b_{t}^{y}\right)^{\prime}$, and $\operatorname{Var}\left(e_{t}^{y}\right)=R$ and $\operatorname{Var}\left(v_{t}\right)=Q$.

The model (22)-(23) can be easily estimated via Gibbs sampling (see Blake and Mumtaz, 2012). Specifically, if the time-varying coefficients $\boldsymbol{\beta}_{t}$ are known, then the conditional posterior distribution of $R$ is inverse Gamma, and the distribution of $Q$ is inverse Wishart. Conditional on $R$ and $Q$ the model (22)-(23) is a linear Gaussian state space model. Since the conditional posterior of $\boldsymbol{\beta}_{t}$ is normal, the mean and the variance of $\boldsymbol{\beta}_{t}$ can be derived with the Kalman filter. ${ }^{17}$

Figure 6 compares time-varying estimates to their static equivalent for the 18 countries in the sample. While some variation is apparent, time-varying estimates of factor loadings are rarely significantly different from their constant counterparts.

\footnotetext{
${ }^{17}$ Appendix B provides the details on the Gibbs sampling algorithm, initial conditions and priors.
} 
Figure 6 Time-varying Estimates Of The Loadings On The First PrinCIPAL COMPONENT
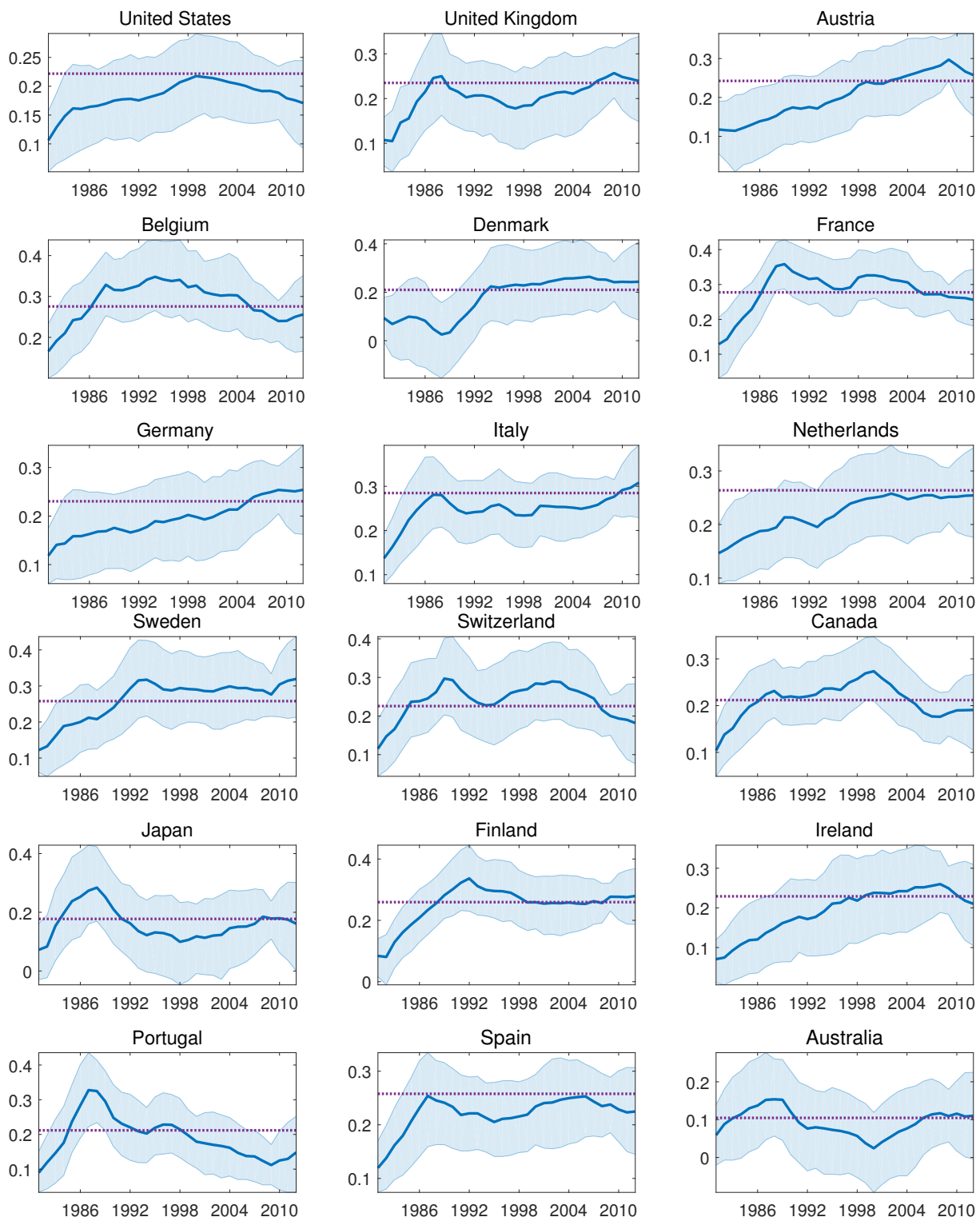

—-Time-varying 16/84 Percentile ........... Fixed (OLS)

Note. Median estimates of the time-varying parameters (solid line) in model (22)-(23). Shaded areas display the 68 percent credible intervals. The dashed line reports the OLS fixed estimates. 
Table 8 reports the results implied when the time-varying estimates of $b_{t}^{y}$ are used to decompose $\mathcal{S}_{i j, t}$ into $\mathcal{S}_{i j, t}^{\mathcal{F}}$, and $\mathcal{S}_{i j, t}^{\varepsilon}$. The estimates of $\beta$ continue to switch signs as in the results presented above: Negative when $\mathcal{S}_{i j, t}$ or $\mathcal{S}_{i j, t}^{\mathcal{F}}$ are the dependent variable, but positive and significant when $\mathcal{S}_{i j, t}^{\varepsilon}$ is. This provides an alternative decomposition where the existence of common shocks obscures the effect of finance on synchronization.

Table 8 Banking Integration and Business CyCle Synchronization: Panel ("Within") Time-Varying Parameter Estimates

\begin{tabular}{lrrrrrr}
\hline & $\mathcal{S}$ & \multicolumn{1}{c}{$\mathcal{S}^{\mathcal{F}}$} & \multicolumn{1}{c}{$\mathcal{S}^{\varepsilon}$} & \multicolumn{1}{c}{$\mathcal{S}$} & \multicolumn{1}{c}{$\mathcal{S}^{\mathcal{F}}$} & \multicolumn{1}{c}{$\mathcal{S}^{\varepsilon}$} \\
\hline & \multicolumn{1}{c}{$(1)$} & \multicolumn{1}{c}{$(2)$} & \multicolumn{1}{c}{$(3)$} & \multicolumn{1}{c}{$(4)$} & \multicolumn{1}{c}{$(5)$} & $(6)$ \\
\hline Banking / Pop. & -0.144 & -0.195 & 0.033 & & & \\
& $(0.040)$ & $(0.037)$ & $(0.012)$ & & & \\
Banking / GDP & {$[-3.63]$} & {$[-5.21]$} & {$[2.68]$} & & & \\
& & & & -0.148 & -0.199 & 0.031 \\
& & & & $(0.042)$ & $(0.040)$ & $(0.013)$ \\
Observations & 4863 & 4863 & 4863 & 4863 & 4863 & 4863 \\
R2 & 0.099 & 0.198 & 0.161 & 0.099 & 0.197 & 0.161 \\
Country Pairs & 153 & 153 & 153 & 153 & 153 & 153 \\
\hline
\end{tabular}

Note. All regression specifications include a vector of country-pair fixed effects and a vector of year fixed effects. Estimation is performed over the 1980-2012 period. Standard errors are adjusted for country-pair-level heteroskedasticity and autocorrelation.

\section{Conclusion}

In the workhorse model of international real business cycles with complete markets, financial flows exacerbate asymmetries in business cycles as they relocate efficiently to the country with highest marginal product of capital. Under mild heterogeneity (e.g., in factor shares) the same model has observationally equivalent predictions in response to a common shock: While productivity changes are identical in both countries, the marginal products of capital respond differently, and so do GDP growth rates. The key difference is interpretation: With common shocks, capital flows respond to countries' fundamental heterogeneity, rather than an efficient quest for high returns. 
To establish whether international capital flows are fundamentally efficient, it is therefore imperative to control for common shocks of a specific kind: Those that are allowed to have heterogeneous effects across countries. Conditional on such common shocks, we find that financial linkages tend to result in less synchronized business cycles in 18 OECD countries. We show this finding is driven by a permanent feature of cross-country heterogeneity (i.e., a systematic correlation between capital flows and countries' GDP elasticity to common shocks), rather than by random, country-specific shocks. In contrast, conditional on well identified idiosyncratic, country-specific shocks we show that financial flows result in more synchronized business cycles in the vast majority of specifications. This finding provides support for the possibility that international financial flows serve to alleviate binding financial constraints, thus fostering contagion. 


\section{References}

Allen, F., And D. Gale (2000): "Financial Contagion," Journal of Political Economy, 108(1), 1-33.

Backus, D. K., P. J. Kehoe, and F. E. Kydland (1992): "International Real Business Cycles," Journal of Political Economy, 100(4), 745-75.

Baxter, M., And M. A. Kouparitsas (2005): "Determinants of business cycle comovement: a robust analysis," Journal of Monetary Economics, 52(1), 113-157.

Bernanke, B., J. Boivin, And P. S. Eliasz (2005): "Measuring the Effects of Monetary Policy: A Factor-augmented Vector Autoregressive (FAVAR) Approach," The Quarterly Journal of Economics, 120(1), 387-422.

Blake, A., And H. Mumtaz (2012): Applied Bayesian econometrics for central bankers, no. 4 in Technical Books. Centre for Central Banking Studies, Bank of England.

Bravo-Ortega, C., And J. Di Giovanni (2006): "Remoteness and Real Exchange Rate Volatility," IMF Staff Papers, 53(si), 6.

Broner, F., T. Didier, A. Erce, And S. L. Schmukler (2013): "Gross capital flows: Dynamics and crises," Journal of Monetary Economics, 60(1), 113-133.

Bruno, V., And H. S. Shin (2014): "Cross-border banking and global liquidity," BIS Working Papers 458, Bank for International Settlements.

- (2015): "Cross-Border Banking and Global Liquidity," Review of Economic Studies, 82(2), 535-564.

Caselli, F. (2005): "Accounting for Cross-Country Income Differences," in Handbook of Economic Growth, ed. by P. Aghion, and S. Durlauf, vol. 1 of Handbook of Economic Growth, chap. 9, pp. 679-741. Elsevier.

Corsetti, G., M. Pericoli, and M. Sbracia (2005): "Some contagion, some interdependence': More pitfalls in tests of financial contagion," Journal of International Money and Finance, 24(8), 1177-1199.

Crucini, M., A. Kose, And C. Otrok (2011): "What are the driving forces of international business cycles?," Review of Economic Dynamics, 14(1), 156-175.

Dedola, L., And G. Lombardo (2012): "Financial frictions, financial integration and the international propagation of shocks," Economic Policy, 27(70), 319-359.

Devereux, M. B., And J. Yetman (2010): "Leverage Constraints and the International Transmission of Shocks," Journal of Money, Credit and Banking, 42(s1), 71-105.

Devereux, M. B., And C. Yu (2014): "International Financial Integration and Crisis Contagion," NBER Working Papers 20526, National Bureau of Economic Research, Inc.

Doyle, B. M., And J. Faust (2005): "Breaks in the Variability and Comovement of G-7 Economic Growth," The Review of Economics and Statistics, 87(4), 721-740. 
Duval, R., N. Li, R. Saraf, and D. Seneviratne (2016): "Value-added trade and business cycle synchronization," Journal of International Economics, 99(C), 251-262.

Forbes, K. J., And R. Rigobon (2002): "No Contagion, Only Interdependence: Measuring Stock Market Comovements," Journal of Finance, 57(5), 2223-2261.

Forbes, K. J., And F. E. Warnock (2012): "Capital flow waves: Surges, stops, flight, and retrenchment," Journal of International Economics, 88(2), 235-251.

Forni, M., And L. Reichlin (1998): "Let's Get Real: A Factor Analytical Approach to Disaggregated Business Cycle Dynamics," Review of Economic Studies, 65(3), 453-73.

Frankel, J. A., And A. K. Rose (1998): "The Endogeneity of the Optimum Currency Area Criteria," Economic Journal, 108(449), 1009-25.

Giannone, D., M. Lenza, and L. Reichlin (2010): "Business Cycles in the Euro Area," in Europe and the Euro, NBER Chapters, pp. 141-167. National Bureau of Economic Research, Inc.

Hirata, H., M. A. Kose, And C. Otrok (2013): "Regionalization vs. Globalization," in Global Interdependence, Decoupling, and Recoupling, pp. 87-130. MIT Press.

ImBS, J. (2006): "The real effects of financial integration," Journal of International Economics, 68(2), 296-324.

IMF (2013): "Dancing Together? Spillovers, Common Shocks, and the Role of Financial and Trade Linkages," in World Economic Outlook, October 2013, world economic outlook 3. Washington: International Monetary Fund.

Kalemli-Ozcan, S., E. Papaioannou, and F. Perri (2013): "Global banks and crisis transmission," Journal of International Economics, 89(2), 495-510.

Kalemli-Ozcan, S., E. Papaioannou, and J.-L. Peydro (2013): "Financial Regulation, Financial Globalization, and the Synchronization of Economic Activity," Journal of Finance, 68(3), 1179-1228.

Kaminsky, G. L., C. M. Reinhart, and C. A. Vegh (2005): "When It Rains, It Pours: Procyclical Capital Flows and Macroeconomic Policies," in NBER Macroeconomics Annual 2004, Volume 19, NBER Chapters, pp. 11-82. National Bureau of Economic Research, Inc.

Kilian, L. (2008): "A Comparison of the Effects of Exogenous Oil Supply Shocks on Output and Inflation in the G7 Countries," Journal of the European Economic Association, 6(1), $78-121$.

Kose, M. A., C. Otrok, and C. H. Whiteman (2003): "International Business Cycles: World, Region, and Country-Specific Factors," American Economic Review, 93(4), 12161239 .

(2008): "Understanding the evolution of world business cycles," Journal of International Economics, 75(1), 110-130. 
Monnet, E., And D. Puy (2016): "Has Globalization Really Increased Business Cycle Synchronization?," IMF Working Papers 16/54, International Monetary Fund.

Morgan, D., B. Rime, And P. E. Strahan (2004): "Bank Integration and State Business Cycles," The Quarterly Journal of Economics, 119(4), 1555-1584.

Mumtaz, H., S. Simonelli, And P. Surico (2011): "International Comovements, Business Cycle and Inflation: a Historical Perspective," Review of Economic Dynamics, 14(1), $176-198$.

Peersman, G., and F. Smets (2005): "The Industry Effects of Monetary Policy in the Euro Area," Economic Journal, 115(503), 319-342.

REY, H. (2013): "Dilemma not trilemma: the global cycle and monetary policy independence," Proceedings - Economic Policy Symposium - Jackson Hole, pp. 1-2. 


\section{A Additional results}

\section{A.1 Heterogeneity in OECD Economies}

Table A.1 provides the values of capital shares and depreciation rates for the countries considered in our main empirical analysis. The data (from Penn World Table, version 8.1) show a high degree of heterogeneity across countries. The share of capital ranges from 0.28 to 0.52 and the depreciation rates from 0.34 to 0.48 . For additional evidence on cross-country heterogeneity see Caselli (2005).

Table A.1 Cross-country Heterogeneity in Capital Shares AND Depreciation Rates

\begin{tabular}{lrr}
\hline & Capital share $(\theta)$ & Depreciation $(\delta)$ \\
\hline Australia & 0.37 & 0.040 \\
Austria & 0.36 & 0.042 \\
Belgium & 0.38 & 0.042 \\
Canada & 0.40 & 0.039 \\
Denmark & 0.34 & 0.040 \\
Finland & 0.37 & 0.037 \\
France & 0.35 & 0.034 \\
Germany & 0.34 & 0.038 \\
Ireland & 0.52 & 0.041 \\
Italy & 0.42 & 0.041 \\
Japan & 0.44 & 0.044 \\
Netherlands & 0.36 & 0.038 \\
Portugal & 0.32 & 0.046 \\
Spain & 0.35 & 0.036 \\
Sweden & 0.33 & 0.048 \\
Switzerland & 0.28 & 0.048 \\
United Kingdom & 0.36 & 0.043 \\
United States & 0.36 & 0.039 \\
\hline
\end{tabular}

Note. Data from Penn World Table (version 8.1). Capital share $(\theta)$ is 1 minus the share of labour compensation in GDP at current national prices; Depreciation $(\delta)$ is the average depreciation rate of the capital stock.

\section{A.2 Principal components}

We compute principal components using the pca command in Stata. In order to be able to use the eigenvalue criterion to select the appropriate number of principal components (as described in the main text), we normalize the data - so that each country-specific growth rate $\left(y_{i t}\right)$ has unit variance. Therefore we can interpret all 
principal component with associated eigenvalues greater than 1 as common to at least two countries.

Figure A.1 reports the estimated first three principal components (from the panel of GDP growth rates $y_{i t}$ ) that are common to 2 or more countries, together with the annual growth rate of World GDP from IMF IFS. The principal component approach is a purely statistical process. While trying to understand what the first, second, or third factors capture is outside of the scope of this paper, we provide some evidence that they are all economically relevant as they are all related with global output growth (correlation coefficients range from 0.16 to 0.69 ).

Figure A.1 Estimated Principal Components and World GDP GROWTH

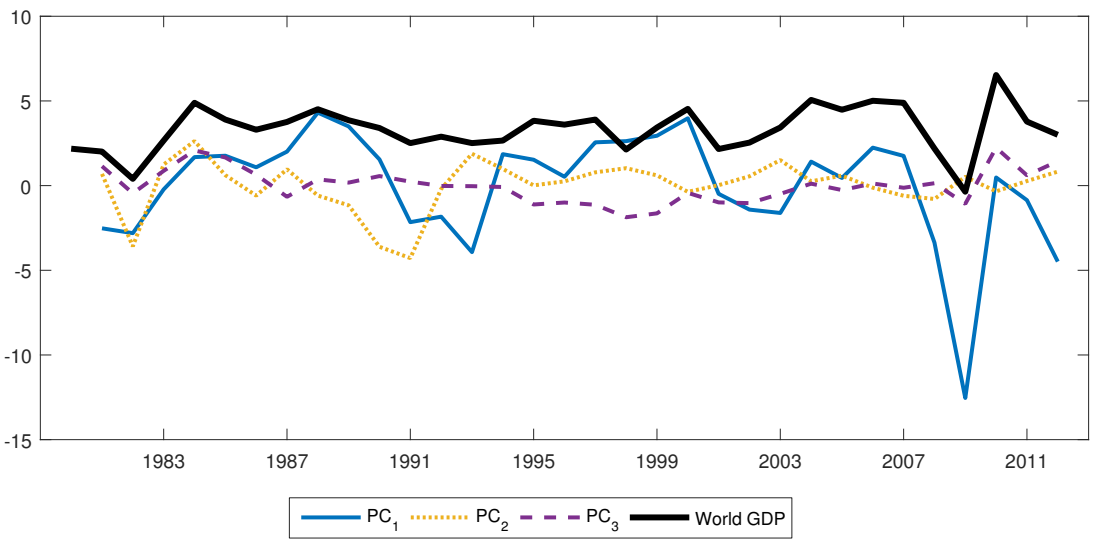

Note. Principal components are computed on the panel of 18 GDP growth series $\left(y_{i t}\right)$. Annual World GDP growth is from IMF International Financial Statistics.

\section{A.3 Factor estimates for the 1980-2006 period}

Table A.2 provides a summary of the factor estimates for GDP growth rates $y_{i t}$ over the period 1980-2006. As in the baseline sample period (that runs from 1980 to 2012), the first three factors explain about 70 percent of the variance of $y_{i t}$. According to the eigenvalue criterion, we retain the same number of factors as in the baseline. 
Table A.2 Factor Estimates For GDP Growth Excluding The Great ReCEssion Years

\begin{tabular}{lrrr}
\hline & Eigenvalues & $\begin{array}{r}\text { Share of } \\
\text { variance }\end{array}$ & $\begin{array}{c}\text { Cum. share } \\
\text { of variance }\end{array}$ \\
\hline $\mathcal{F}_{1}$ & 5.27 & 0.42 & $42 \%$ \\
$\mathcal{F}_{2}$ & 2.61 & 0.21 & $63 \%$ \\
$\mathcal{F}_{3}$ & 1.09 & 0.09 & $71 \%$ \\
$\mathcal{F}_{4}$ & 0.91 & 0.07 & $78 \%$ \\
$\mathcal{F}_{5}$ & 0.84 & 0.07 & $85 \%$ \\
\hline
\end{tabular}

Note. Principal components are computed on the panel of 18 GDP growth series $\left(y_{i t}\right)$ over the sample period 1980-2006.

\section{B Estimation of time-varying parameters model}

Consider the time-varying parameters model in (22)-(23). The Gibbs sampling algorithm consists of the following steps:

1. Set starting values (i.e., $\left.\beta_{0}, \operatorname{Var}\left(\beta_{0}\right), R_{0}, Q_{0}\right)$ and priors

$$
\begin{aligned}
& \mathcal{P}(R) \sim \mathcal{I} \mathcal{G}\left(\frac{T_{0}}{2}, \frac{\theta^{R}}{2}\right) \\
& \mathcal{P}(Q) \sim \mathcal{I} \mathcal{W}\left(\frac{T_{0}}{2}, \frac{\theta^{Q}}{2}\right)
\end{aligned}
$$

2. Sample the state variable $\beta_{t}$ conditional on $R$ and $Q$ from its conditional posterior distribution using the Kalman filter

3. Using $\beta_{0}$ and $\operatorname{Var}\left(\beta_{0}\right)$ run Kalman Filter to get mean and variance of $\beta_{t}$ at each point in time

4. Conditional on $\beta_{t}$, sample $Q$ and $R$ from their posterior distributions.

5. Repeat steps 1 to 3 until convergence is detected.

Below we describe how we proceed in detail.

Setting $\beta_{0, i}, \operatorname{Var}\left(\beta_{0, i}\right)$, and $R_{0, i}$.

We compute a fixed parameter version of model (21) on the full sample for all countries. Therefore, for each country $i$, we get an estimate of $\beta_{0, i}, \operatorname{Var}\left(\beta_{0, i}\right)$, and 
$R_{0, i}$ :

$$
\begin{aligned}
\beta_{0} & =\left(X_{t}^{\prime} X_{t}\right)^{-1}\left(X_{t}^{\prime} Y_{t}\right) \\
\operatorname{Var}\left(\beta_{0}\right) & =R_{0} \otimes\left(X_{t}^{\prime} X_{t}\right)^{-1} \\
R_{0} & =\frac{\left(y_{t}-X_{t} \beta_{t}\right)\left(y_{t}-X_{t} \beta_{t}\right)^{\prime}}{(T-K)}
\end{aligned}
$$

where $T$ denotes the number of observations.

Setting $Q_{0, i}$.

Since $Q_{0}$ is unobserved, one could do a rolling window OLS estimation of the fixed parameter model to get a time-varying estimate of $\beta_{0}$. Then, an estimate of $Q_{0}$ can be obtained by running an $\operatorname{VAR}(1)$ model on the rolling estimates of $\beta_{0}$ :

$$
\beta_{0, t}=\Phi \beta_{0, t-1}+\xi_{\tau} .
$$

and recovering the covariance matrix of $\xi_{t}$ in equation (B.6) as:

$$
Q_{0}=\frac{\left(\beta_{0, t}-\Phi \beta_{0, t-1}\right)\left(\beta_{0, t}-\Phi \beta_{0, t-1}\right)^{\prime}}{(T-K)} .
$$

For the above procedure to work we clearly need a large number of observations. The sample has to be large enough to allow for a rolling window estimation. The annual frequency of our data set creates a limitation for the implementation of the strategy. We increase the number of available observations using a quarterly data set that is comparable to our annual data set (quarterly real GDP data from the OECD from 1980:Q1 to 2012:Q4).

We then estimate a fixed parameter version of model (21) using a rolling window. To do that, we use a window of 40 quarters.

We then estimate a $\operatorname{VAR}(1)$ model as in (B.6) on the rolling estimates and compute variance-covariance $Q_{0, i}$ for each country.

\section{Setting the priors}

Conditional on $\beta_{t}$ the posterior distribution of $R$ is inverse Gamma and the posterior distribution of $Q$ is inverse Wishart:

$$
\mathcal{P}(R) \sim \mathcal{I} \mathcal{G}\left(T_{0}, \theta^{R}\right) \quad \text { and } \quad \mathcal{P}(Q) \sim \mathcal{I} \mathcal{W}\left(T_{0}, \theta^{Q}\right) .
$$

We set $T_{0}=32$, i.e. the number of observations in our (annual) sample. We then set $\theta^{R}$ so that the mean of $\mathcal{I} \mathcal{G}\left(\frac{T_{0}}{2}, \frac{\theta^{R}}{2}\right)$ matches $\operatorname{Var}\left(e_{t}\right) \equiv R_{0}$ and the mean

of $\mathcal{I} \mathcal{W}\left(\frac{T_{0}}{2}, \frac{\theta^{Q}}{2}\right)$ matches $\operatorname{Var}\left(v_{t}\right) \equiv Q_{0}$. Therefore, for $\mathcal{P}\left(R_{i}\right) \sim \mathcal{I} \mathcal{G}\left(T_{0, i}, \theta_{i}^{R}\right)$ we 
set $\theta_{i}^{R}=R_{0, i}\left(T_{0, i}-1\right)$. For $\mathcal{P}\left(Q_{i}\right) \sim \mathcal{I} \mathcal{W}\left(T_{0}, \theta_{i}^{Q}\right)$ we set the diagonal element $\theta_{n n, i}^{Q}=Q_{0, i}\left(T_{0}-n-1\right)$.

\section{Implementation}

We run 100,000 replications, discard the first 99,000, and use the remaining 1,000 draws to form the empirical distribution of the parameters of (22)-(23) 